\title{
Hermenéutica en Filológicas. Notas para conversar
}

Hermeneutics at the Instituto de Investigaciones

Filológicas. Notes for a conversation

Manuel Lavaniegos

Universidad Nacional Autónoma de México

\begin{abstract}
RESUMEN: El artículo, a manera de puntos problemáticos y propositivos, busca definir mínimamente el campo de estudio de la Hermenéutica, en su sentido contemporáneo, así como esbozar sus relaciones esenciales con las labores de la filología. El entendimiento, la traducción e interpretación de los textos en el devenir de las tradiciones culturales, como factor clave en sus crisis de transformación y complejización - al ser enfocado a partir del impacto del llamado "giro lingüístico-hermenéutico"-, conduce hacia una comprensión ampliada del carácter polifacético y políglota inherente a todo lenguaje con alcances filosóficos (epistémicos y ontológicos); lo cual viene a redibujar el panorama actual de las zonas y perspectivas de las ciencias humanas, posibilitando un entrelazamiento heurístico entre la hermenéutica y la filología. Con estas anotaciones abiertas al diálogo se concibe, también, la pertinente inscripción del Seminario de Hermenéutica en el Instituto de Investigaciones Filológicas de la UNAM.
\end{abstract}

ABSTRACT: This paper aims to define concisely the field of study of contemporary hermeneutics, outlining its important relationship with the tasks of philology. Throughout the history of cultural traditions, practices of text comprehension along with translation and interpretation, comprised in the definition of hermeneutics, have led to a deeper understanding of the diversity and polysemic nature of philosophical languages. Based on the so-called "linguistic-hermeneutic turn", this approach seeks to offer a completely new outlook of today's perspectives for human sciences. This way a heuristic intersection between hermeneutics and philology becomes feasible. Open to discussion, these notes also greet the inclusion of the Seminario de Hermenéutica in the Instituto de Investigaciones Filológicas (Institut of Philological Researches) at the UNAM.

PALABRAS CLAVE: hermenéutica, filología, giro lingüístico-hermenéutico, alteridad-traductibilidad, líneas de investigación hermenéuticas.

KEY WORDS: hermeneutics, philology, linguistic-hermeneutic turn, alterity-translation, lines of hermeneutic research.

RECIBIDO: 17 de enero de 2015 - AcEPTADO: 24 de abril de 2015 

Manuel Lavaniegos

Universidad Nacional Autónoma de México

\section{Hermenéutica en Filológicas. Notas para conversar}

- La hermenéutica o hermeneutiké tekhnē - en su acepción griega originaria, entendida básicamente como el arte ("saber hacer") del hermeneuein, de la transmisión, la mediación y la interpretación de los mensajes, de los textos - emerge, de hecho, como una consciencia y actividad necesaria a raíz de la extensión, intensidad y complejización que adquiere la diversidad de conocimientos, saberes y discursos en el seno de las sociedades humanas; estas mismas sujetas a procesos históricos de crecimiento y transformación, relativamente ineludibles.

Podemos afirmar, en principio, que la génesis de la hermenéutica ${ }^{1}$ no es otra cosa que el desarrollo de la consciencia o comprensión de

1 El filósofo italiano Maurizio Ferraris en su Historia de la hermenéutica (2002) examina, en el primer capítulo de su libro, las distintas acepciones y las vicisitudes que va teniendo la hermenéutica a lo largo de la Antiguiedad y el Medioevo; desde su vinculación originaria con los mensajes religiosos oraculares (exegesis), su subsunción antigua en el arte de la retórica, su consideración de habilidad menor frente a la episteme filosófica (Platón y Aristóteles), su constitución filológica durante el Helenismo, con las escuelas de Antioquía y Alejandría, hasta la complejidad de sus usos por la Patrística y la Escolástica. Para, posteriormente, durante la Ilustración, pero sobre todo a partir del Romanticismo, pasar de ser técnicas o habilidades auxiliares, aplicadas principalmente a la teología, la jurisprudencia y la traducción, a convertirse en reflexión con pretensiones filosóficas; con Schleiermacher, Droysen o Dilthey se comienza a postular la hermenéutica como la clave de unificación del conjunto de las “ciencias del espíritu”. Véase también Grondin 1999. 
la "problematicidad" inherente a la complejización del lenguaje o, mejor dicho, de los diferentes lenguajes humanos; ${ }^{2}$ entendidos éstos como las distintas formas o modos de articulación significativa-comunicativa que han elaborado los hombres de su realidad, de su mundo. Más precisamente, el lenguaje, el habla, son concebidos - a partir del giro hermenéutico contemporáneo - no tanto como instrumentos o medios de comunicación para expresar reflejamente (a modo de copia) cosas del mundo o pensamientos mentales previos, sino como el lugar, medium, esencial para el acontecer mismo del "mundo", de revelación del ser, y como proceso consustancial para la emergencia y despliegue del pensamiento. H.-G. Gadamer escribe: "El lenguaje es un centro en el que se reúnen el yo y el mundo, o mejor, en el que ambos aparecen en su unidad originaria" (1977: 567).

- También podemos coincidir en el papel preponderante que juegan las palabras y las imágenes como elementos primordiales en ese proceso de construcción cognoscitiva e imaginativa del sentido interhumano del entorno natural y su mundo social. El lenguaje comprendido como medio-medium, materialidad y atmósfera, del transcurrir tanto del orden del logos (pensar/decir) como del drama del mythos. Ello nos revela fundamentalmente al hombre como un homo parlante, constructor de sistemas de signos pero, también, como capax symbolorum, creador de símbolos, de signos más complejos, analógicos y polisémicos, capaces de evocar "lo ausente", lo que ya no es y lo que aún no es.

Direcciones plenamente imaginales o arcanas hacia el origen ancestral (protología) y hacia el futuro utópico o mesiánico (escatología), a las cuales sólo podemos aludir por la vía de la consciencia indirecta, a través de los significantes sensibles, perceptibles del símbolo, compuestos por referentes del mundo que nos rodea. Am-

2 Nos atenemos al criterio de G. Ebeling ("Hermeneutik", en Die Religión in Geschichte und Gegenwart), quien escribe: "El significado del vocablo [hermenéutica] es buscado en tres direcciones: aseverar (expresar), 'interpretar' (explicar) y traducir (ser intérprete). No se trata de establecer cuál sea, lingüística e históricamente, el significado primario. Se trata de modificaciones del significado fundamental de 'conducir a la comprensión', de 'mediar en la comprensión' respecto de los diferentes modos de plantearse el problema del comprender" (citado por Ferraris 2002: 11-12). 
bas dimensiones simbolizadas, sin embargo, permanecen enigmáticas, en última instancia insondables — ¿de dónde venimos? ¿a dónde vamos?-, constituyéndose así, como lo había pensado Nietzsche, en claves imprescindibles para situar y orientar nuestra condición presente temporalizada o nuestro sentido de "ser en el mundo" - ¿quiénes somos?-, con la implicada tensión entre reminiscencias y olvidos ante el reto del umbral o "arco del instante" (Nietzsche 1963). Justamente el relato mítico (pero también las recreaciones literarias, autobiográficas o "historias que nos contamos unos a otros" y, de manera involuntaria, las oníricas), con sus personajes y episodios simbólicos (mitologemas ${ }^{3}$ ) eslabonados por su trama, puede ser enfocado como un primer logos simbólico que intenta, al menos provisoriamente, dar forma o dotar de un cierto orden a nuestra duración finita en la infinitud del universo; tramar la temporalidad significativa (cosmos) de nuestra existencia ante los caóticos avatares contingentes que, a cada paso, le asaltan. En este sentido, el vértigo ante el abismo de nuestra condición temporal es indisociable de la poiesis, que expresa su patetismo, su suspense, e intenta darle forma, "hacerlo aparecer".

- En virtud de estas proposiciones básicas, a su vez, puede entenderse el monumental protagonismo que posee la palabra - en su doble vertiente: "hablada" y "escrita"-, es decir la directa, "natural", transmitida oralmente o dialogada, en una dinámica de pregunta-respuesta, y la escriturada, plasmada gráficamente; y, con ello, susceptible de adquirir otros tantos modos de reproductibilidad, justo como atinadamente observó Roman Jakobson (1975), adjudicándole el mayor rango de "traductibilidad"; poder de traductibilidad que poseen los "lenguajes natural/culturales", productores o creadores de palabras, y con ellas de discursos, de textos, en medio de la exuberancia polifacética de la expresividad humana. Es decir, capacidad de poder empalabrar (Duch 1998), decir, narrar o explicar, analógicamente, algo acerca de las otras modalidades - "no-verbales": ges-

3 La noción de "mitologema" es usada y explicada por Karl Kerényi en su notable ensayo "Del origen y el fundamento de la mitología" (Jung y Kerényi 2003: 15-41). 
tuales, plástico-visuales, sonoro-musicales, etc.- de expresividad, de imaginación y de pensamiento o de configuración significativa que despliega, en su praxis, el cuerpo/psique del anthropos para habitar la Tierra.

Sólo que hay que aclarar, de inmediato, que las palabras únicamente "dicen", "describen" o "traducen" en algo lo que las imágenes gestuales, sonoras, visuales, táctiles, olfativas, sinestésicas, etc., expresan, sin llegar nunca a sustituir la irreductible significación concreta que estas formas de lenguaje, con su densidad o textura cualitativa peculiares, otorgan a nuestra experienciada realidad.

- En esta misma dirección es que podemos referirnos a la "interpretación" de textos, desde una muy amplia generalidad: de textos hablados, escritos y actuados, como "acciones", performáticas, susceptibles de ser analizadas cual textos actuados, despliegues del Verbum, o praxis que poseen cierta codificación significativa, y se han configurado como obras (dromenon), monumentos o puestas en acto (mises en scène). Todo ese amplio campo que la lingüística investiga al extenderse en semiótica; pero que, también, atañe a la retórica y a la pragmática del lenguaje cuando exploran los modos comunicativos de "interpretación" de textos, que, por supuesto, repercuten sobre su semantismo y su sentido. Pero, la propia generación del sentido en el habla, en el texto, en la creación y la recepción (recreación) de la obra, es ya, de por sí, esencialmente interpretación que se da, que acaece, en nuestra comprensión de lo real, como una singular, específica expresión de un modo de ser en el mundo.

- Hay que apresurarse a puntualizar que la "universalidad ontológica" del fenómeno del lenguaje en la existencia humana, que se trasluce en nuestras afirmaciones anteriores - en el sentido de que no hay posibilidad de cultura humana extralingüística-, representa, de suyo, una de las postulaciones esenciales del mencionado "giro" (Kehre) hermenéutico, sobre todo protagonizado por M. Heidegger, H.-G. Gadamer y P. Ricoeur, que vino a proyectar el alcance de la hermenéutica misma, del estatuto de disciplina humanista más o menos auxiliar al centro de gravedad polémico del pensamiento filosó- 
fico actual. Sin embargo, el lema enunciado por Gadamer de que "el ser que puede ser comprendido es lenguaje" ${ }^{4}$ - complementario a la expresión usada por el Heidegger tardío del lenguaje como "casa del ser" (1987; 2005), o la de Wittgenstein del "lenguaje como límite del mundo" $(1973)^{5}$ - no quiere decir la afirmación de una "panlinguiística" acrítica sin más sino, por el contrario, la proposición que otorga al lenguaje un estatus ontológico, como el cosmos significativo en que vivimos los finitos seres humanos, trae implicada, al mismo tiempo, la consciencia de sus límites intrínsecos, plenamente historizados y condicionados por nuestra perspectiva finita. Pues, si el lenguaje, ya sea verbal o no-verbal, posee "la capacidad de buscar expresiones para todo" y en él se realiza el "entender", sin embargo, no agota ni puede con sus enunciados abarcar nuestra total experiencia de ser en el mundo y su permanente estar abierta a lo otro, a la alteridad; con todo lo que ésta conlleva de indecible, inefable

4 "El ser que puede ser comprendido es lenguaje. El fenómeno hermenéutico devuelve aquí su propia universalidad a la constitución óntica de lo comprendido cuando determina ésta su sentido universal como lenguaje, y cuando entiende su propia referencia a lo que es como interpretación. Por eso hablamos no sólo de un lenguaje del arte, sino también de un lenguaje de la naturaleza, incluso de un lenguaje de las cosas" (Gadamer I977: 567).

5 Asimismo, tal vez más nítidamente expresado por Fiódor M. Dostoyevski: "El hombre es la Palabra encarnada. Existe para ser consciente de Ella y para expresarla" (Los hermanos Karamázov).

"El hombre es la Palabra encarnada" que dice Dostoyevski puede, pienso, ser entendido también en indisoluble co-implicación o co-referencialidad con los sentidos corporales, con la dimensión percipiente/percibida que atraviesa siempre enlazándolos al lenguaje y al cuerpo. La "Palabra encarnada" inervando, por completo, a la "carne", a la potencia afectiva-deseante de la fenomenología del cuerpo (Merleau-Ponty), estallando o aflorando en la palabra: un vaivén incesante "intraontológico" de corporeidad y lenguaje. El alma ("voz") del cuerpo soplando en el espíritu de la palabra, de la letra, y viceversa. Como en el ralentizado parpadeo que retiene Georges Bataille, con el suspenso de la escritura, en La experiencia interior: "Mis ojos se han abierto, es verdad, pero habría hecho falta no decirlo, permanecer fijo como un animal. He querido hablar y, como si las palabras portaran el peso de mil sueños, suavemente, como pareciendo no ver, mis ojos se han cerrado" (Bataille 1989: 25).

La poeta argentina Alejandra Pizarnik expresa de manera más quintaesenciada la condición paradójica del lenguaje, con poética sutilidad, contundente y dramática: "Por amor al silencio se dicen miserables palabras [...] por amor al lenguaje de los cuerpos [..... Deseaba un silencio perfecto/por eso hablo" (1992: 20). 
e "indisponible". Porque, también, escribe Gadamer: "Lo que está expresado no es todo. Sólo lo no dicho convierte lo expresado en la palabra que puede alcanzarnos" o, como en el verso del poeta R. M. Rilke:

Bienaventurados los que saben que más allá de todos los lenguajes existe lo Inefable.

Muy cerca, a su vez, de Wittgenstein, que en el Tractatus escribe: "Hay ciertamente, lo inexpresable, lo que se muestra a sí mismo; esto es lo místico" (1973: 203). ${ }^{6}$ Indecibilidad que apunta a la existencia abierta al ser del mundo; "que el mundo sea".

- Ha sido el filósofo Jean Grondin el que ha puesto de relieve la importancia que presenta la doctrina estoico/agustiniana del verbum interius para la perspectiva hermenéutica de Gadamer, la "palabra interior" no pronunciada pero que resuena en toda expresión del lenguaje, y que convierte la universalidad del lenguaje esencialmente no en una sustancia dada absolutamente determinada y determinante, sino en una "búsqueda de lenguaje". Pues, siempre hay un "querer decir” una intención que va más allá de lo ya expresado por las palabras enunciadas o formulado por las proposiciones, siempre insatisfecho en busca de una "otra" palabra aún más acertada que alcance al otro, y que deja traslucir el carácter constitutivo abierto del lenguaje como diálogo; estructurado por la tensión alterna de pregunta-respuesta. "La dimensión universal que mantiene la hermenéutica en acción es, por tanto, la de la palabra interior, del diálogo del que toda expresión recibe su vida". El lenguaje se presenta, así, como la encarnación de la única mediación - siempre provisoria - para ese inagotable "diálogo (interior) que somos para nosotros mismos y que somos los unos para los otros" (Grondin 1999: 157-158).

Asimismo, Adriano Fabris en su ensayo El giro lingüístico y análisis del lenguaje, en torno al desbordamiento mismo de la procesualidad dialogal de la esencial búsqueda del lenguaje, vuelve, de

6 Véase, también, Hadot 2009:128-129. 
nuevo, a remitir el fondo de su comprensión e interpretación hacia el horizonte de la alteridad:

De hecho, "experiencia" no quiere decir sólo comprensión y asimilación de aquello que se presenta a nuestra mirada; ni indica únicamente la disponibilidad a situarse en el horizonte trazado por las estructuras de la lengua que hablamos. "Experiencia" significa sobre todo - en conformidad con lo tomado del pensamiento griego- capacidad de admiración, posibilidad de sorprenderse por lo de antemano imprevisible, y continua remisión a algo que escapa inicialmente a todo vínculo de reciprocidad. En otras palabras, el término "experiencia" define la originaria apertura a lo otro, es por constitución experiencia de lo otro (Fabris 2001: 52).

- Retornando a ese señalado mayor rango de "traductibilidad" que cualifica a las palabras, según la observación de R. Jakobson, queremos aludir a él porque precisamente, pensamos, va de la mano de la labor filológica; ahí se cifra su posibilidad, concebida como una actividad concentrada en la escucha, la captación, el resguardo, la traducción y la transmisión de los textos. Más aún, la filología persigue la máxima posibilidad de trasladar en su integridad, veracidad o singularidad el sentido - como proverbialmente se dice: "el espíritu detrás de la letra" - que late en los signos, en los mensajes que componen los textos más fundantes o representativos y singulares de una cultura.

El filólogo, con su dedicación al cuidado de la textura o urdimbre en que se hila el peculiar entender humano de un mundo, se ve obligado a tener que aprenderlo e interpretarlo a la luz de la propia trama del lenguaje del mundo que lo envuelve. Es decir, de modo ineludible, el filólogo "mira" o lee el texto que le lega una tradición desde el interior de la suya propia, apostado, situado, en su precomprensión o pre-juicios de comprensión del mundo, ${ }^{7}$ desde las

Usando aquí el término "prejuicios" en la acepción revalorizadora, positiva, que les otorga Gadamer (1977), de juicios previos o nociones y orientaciones valorativas de lo real compartidas por un grupo en una época determinada, que operan, en un juego específico de certezas e incertidumbres, para la captación, interpretación y efectuación de su contexto. De hecho, los prejuicios componen los elementos de visibilidad e inteligibilidad contextuales decisivos, en el oficio de vivir y pensar, que provee una tradición. Gadamer considera al hombre como un ser esencialmente tradicional, en la 
celosías valorativas, tanto afectivas como intelectuales, de su propia individualidad y la del universo cultural en el que se encuentra inscrito. El filólogo/intérprete entra, así, en el circuito de pregunta-respuesta del verbum interius del autor resguardado, latente en el texto, que respira y habla dentro de la atmósfera epocal o peculiar Weltanschauung donde fuera engendrado, atmósfera distinta de la suya propia, que le es relativamente lejana o enrarecida, e intentará, entonces, la difícil empresa o peripecia de la traslación de la preciosa chispa vital del texto, sin dejar que fenezca en ese transporte.

El filólogo tendrá que echar mano de todos los recursos documentales, históricos, científicos, artísticos y filosóficos a su alcance para intentar restituir, tanto objetiva como imaginalmente, en lo más posible aquel ambiente dialogal originario ya desaparecido y, sin embargo, pulsante en las huellas o ecos del texto, procurando injertar aquel brote personal del autor de otro mundo lingüístico en el árbol literario de su actual circunstancia. Siempre con la mira de ampliar, con aquel horizonte insustituible - conceptual, ético y estético-, que emana de la obra, los dilemas del propio horizonte, e inclusive, con ello, echar luz, remover y profundizar los prejuicios o verdades dadas por garantizadas en su contemporaneidad. Gaetano Righi, en su breve y pedagógica, pero sustanciosa, Historia de la filología clási$c a$, cita al estudioso ovidiano Antonio Bernardini, acerca de la labor filológica: "se trata de hacer que concuerden la emendatio y la recensio con la interpretatio" (1969: 236).

Entonces, podemos estar de acuerdo en que la labor filológica es una acción eminentemente interpretativa de los textos - que, como apunta G. Ebeling: asevera, explicita y traduce-interpretando-. Es decir, que en el despliegue del propio desempeño filológico brota la realización del momento implicado de su hermeneusis, como una

medida en que siempre es un heredero, que comprende y se desempeña en el mundo a partir de las premisas recibidas de las generaciones anteriores. Así, siempre se halla inmerso, consciente o inconscientemente, en el flujo de una determinada tradición, interpretando la realidad desde esa precomprensión, y sus posibilidades de libertad o de invención no son, en su fondo, sino una re-interpretación de la tradición, una transformación comprensiva posibilitada por los prejuicios en los que se formó, a los que prolonga, al mismo tiempo que altera su rumbo. El proceso de la tradición aparece, así, como el imprescindible nexo de continuidad de la cultura. 
autoconsciencia que tiende a profundizar en las dificultades a las que se enfrenta en su necesaria intelección de los textos. George Steiner lo dice, de modo escueto: "entender es traducir" y lo problematiza detenidamente como un proceso de "desplazamiento hermenéutico" (2001: cap. V).

El acto filológico - en el que van de la mano traducción, comentario crítico y ecdótica-, en su profundización, suscita el tránsito crítico donde se interroga sobre sus propios presupuestos interpretativos (precomprensión) en referencia con los del autor, el texto y el nuevo contexto de su recepción; proyectándose, de esta forma, en el círculo propio o específico de las interrogantes de la hermenéutica, sobre la posibilidad y los límites de la comprensión de la compleja intersección entre contextos históricos y trayectos biográficos. Con ello, la filología misma se halla en su núcleo proyectada, desde los saberes o ciencias humanas que en su quehacer cultiva, hacia el horizonte crítico/filosófico propio de las preguntas hermenéuticas.

Pues la filología se encuentra operando reflexivamente, en primera instancia, sobre todos y cada uno de los momentos constitutivos del proceso de la vida del lenguaje, porque al interrogarse acerca de las "raíces" gramaticales y lexicográficas de las lenguas y sus literaturas - al preguntarse por el "de dónde" y "hacia dónde" que estructuran con su tensión las diferentes configuraciones sígnicas-, no está sino re-tejiendo o suturando con su "interpretación" el completo trayecto comunicativo del lenguaje; es decir, recorriendo de nuevo el acto productivo contextualizado, a la peculiar codificación sígnica del texto, a su recepción o decodificación, que lo re-contextualiza en un acto interpretativo.

- Aunque las aseveraciones anteriores no sean sino en extremo elementales, sin embargo, permítasenos continuar preguntando: ¿a qué obedece la necesidad de la continua re-interpretación de los lenguajes, de los textos, la emergencia misma del discurso filológico y, a su vez, su ampliación en la hermenéutica filosófica? Se puede responder, precisamente, que obedece al carácter, de hecho, cambiante de los contextos - de consistencia, inherentemente, "por naturaleza", polifacéticos y políglotas - , que en su relativamente incesante trans- 
formación empujan a una generatividad en el seno del lenguaje, desde sus más simples fonemas, a la fuerza encriptada que poseen los nombres, hasta los usos y tipos más sofisticados de discursividades. Es decir, que la traslación-interpretativa se realiza fundamentalmente para suturar, vincular o traducir un décale, un desnivel, distancia o abismo - temporo/espacial: histórico, geográfico, sociocultural, científico, político-moral, estético, religioso... en resumen, espiritual-, que surge ya sea al interior de una misma tradición discursiva, debido a las situaciones inéditas o contingencias que se intercalan en la experiencia del paso de las generaciones - lo que ya, en cierto modo, como señalamos, implica un tener que asumir la alteridad-, o ya sea externo, provocado por el encuentro, migración, intercambio o conflicto con otra u otras cultura(s).

Esta interiorización, seductora o forzada, de la alteridad, que acarrean las vicisitudes cotidianas e históricas que jalonan una cultura, produce huecos, quiebres, fallas comunicativas, que obligan a la traductibilidad, a la re-interpretación de los códigos tradicionales, a la elaboración o re-invención de nuevas vías comunicativas y metaforizaciones, de géneros y retóricas, a fin de re-establecer, analogar o conjugar las "diferencias"; las cuales, sin embargo, van coloreando, dejando sus improntas peculiares, introduciendo innovaciones (hibridaciones o mestizajes), en los flujos comunicativos y pedagógicos, memoriosos e imaginales, que son las tradiciones.

Es en este último sentido que tanto Gadamer como Steiner dan un "giro" favorable al episodio bíblico de la confusión de las lenguas que dejó inacabada la erección hasta el cielo de la mítica Torre de Babel, pues la diversificación y la diseminación linguiística más que una catástrofe comunicativa vino a significar un kairós, un acontecimiento propicio para el enriquecimiento diferenciado de las culturas humanas en su habitar planetario, y una apertura hacia la posibilidad de su traductibilidad como espacio comprensivo de sus diversos caminos. A la vez, significaba el radical desplome de la peligrosa pretensión de erigir un monolingüismo totalizante, homogeneizador y aplastante de cualquier diferencia o disidencia; en esto, análogo al fracaso utopista de la síntesis idiomática general y abstracta del "esperanto", o de la univocista búsqueda antimetafísica de R. Car- 
nap, de construir un "lenguaje perfecto" basado en el puro análisis lógico de las proposiciones, en una suerte de metalenguaje regulado filosófica y científicamente, que eliminase cualquier incongruencia y grosería de las lenguas sospechosas de aberraciones y vuelos trascendentes. $^{8}$

De tal manera que podemos comprender el carácter y la misión de las actividades, saberes o artes de la filología y de la hermenéutica como consustancialmente intra-culturales e inter-culturales, en la misma medida en que "para el hombre no hay posibilidad extracultural”, y que la adquisición cultural se articula siempre a través del poliglotismo y polifacetismo inherentes al proceso, simultáneamente común y diversificado, de los lenguajes humanos en su devenir. ${ }^{9}$

- Este carácter polifacético y políglota esencial al despliegue comunicativo del lenguaje corresponde a la propia dinámica de la "complejidad" del fenómeno humano, que el ethos de la labor filológica y hermenéutica no hace otra cosa que intentar entender y restituir, sin reducir ni mutilar dicha complejidad. Justamente, porque deben de ser conscientes de la impronta de libertad creativa irrumpiendo en el seno de los lenguajes - proveniente tanto de los trayectos biográficos de los individuos como de los históricos de los grupos sociales-, fieles a la comprensión del momento de poiesis, de "irrupción" productiva, de innovación diferencial o, para mejor decirlo, de singular re-creación de los códigos tradicionales, en esa indisociable "dialéctica tradición/innovación" implicada en todo genuino acto creador del lenguaje, a la que se refería Octavio Paz. En este sentido, la filología y la hermenéutica no se casan con la unívoca fijeza de un "canon" con pretensiones de "regulación ortodoxa", o de absolutez, con relación al significado o sentido de los textos, sino que permanecen siempre alertas a las alteraciones o "herejías" que brotan, inevitablemente, latentes en los resquicios como verbum interius de los textos, ese tratar de "decir lo indecible", por medio de otras expresiones, que escapan a lo ya dado y a lo ya enunciado. De donde

8 Véase Steiner 2001 y el texto de Gadamer 1997. Así como Fabris 2001.

9 Véase la importante contribución de Duch y Chillón 2012. 
conviene, para la filología y la hermenéutica, el tener que estar atentas a la facticidad, o como diría Heidegger (2008), ${ }^{10}$ a las "pre-estructuras del entender", modos primordiales de interpretar algo, o habérselas con las cosas, con el mundo, en los cotidianos "modos del existir" (Dasein), del "cuidado" (Sorge) o las proyectividades inherentes a la "vida fáctica"; a lo que habría que agregar el carácter de plena historicidad que atraviesa a lo fáctico, sujeto a la irrupción de lo imprevisible.

Esta virulencia de la "flecha" hacia la facticidad es lo que les ha dado y les exige siempre de nuevo, a la filología y a la hermenéutica, el hecho de consistir en un trabajo esencialmente inter-disciplinario o trans-disciplinario, que tiene que recurrir al entrecruce del conjunto de las ciencias humanas o de los diferentes ámbitos de la cultura para realizar su traslación/interpretación; esa exigencia de "espíritu humanístico" que tiene que impregnar plenamente a la filología, como insiste G. Righi (1969). Pues la alteración o las transformaciones del entendimiento y la imaginación humanas en el seno de los lenguajes, provienen de la fuerza de una facticidad que, de continuo, desborda los enunciados ya estabilizados como "objetos de conocimiento", y que reta, a cada paso, la normalizada y especializada institucionalización de la acción humana y su discursividad disciplinaria, confinada en esferas separadas, ajustadas a metodologías científicas infalibles. ${ }^{11}$

10 Tan sólo tomando la sugerencia heideggeriana de la temática: "Facticidad - ontología - ser - ocasionalidad - existir; referidos a la hermenéutica. Todas las indagaciones (deben) comenzar en el ahora mismo y (ser) de modo concreto siempre deconstructivas de lo histórico decisivo determinado. Por razón de la ocasionalidad concreta de la indagación, debe verse empujada al retorno y la apropiación expresa; protegerse del sistema y de una filosofía redonda que uno asume y cree. Ver de modo más positivo: la investigación de la facticidad en la necesidad histórica" (2008: 135-136).

11 Resulta interesante consignar aquí los cuatro rasgos esenciales de la labor filológica planteados por Gaetano Righi:

"De modo que, en conclusión los rasgos propios de la filología, que es inseparable del espíritu humanístico y del paso que éste implica a ulteriores exigencias, son los siguientes:

1) requiere y atestigua, suscita y mantiene el esprit de finesse;

2) necesita el apoyo de una forma sensible y representativa, esto es, surge y se realiza en presencia textual;

3) educa el sentido positivo de lo concreto, evitando generalizaciones, la superficialidad, el dilettantismo del que habla de oídas o por boca de ganso y, a la vez, 
- Ampliando esta óptica filológico/hermenéutica al escenario polémico del discurso propiamente filosófico contemporáneo, podemos, asimismo, comprender que el llamado "giro hermenéutico", que afecta tanto a las ciencias humanas como a la misma filosofía $-\mathrm{y}$ el cual, en toda la integridad de sus alcances tal vez debe ser enunciado, al menos, como un giro lingüístico-hermenéuticoantropológico, ${ }^{12}$ con las implicaciones ontológicas y epistémicas que conlleva-, emergió como resultado del decurso en crisis de la filosofía occidental, que se remonta al panorama en quiebra del sistema hegeliano y, con éste, de los diversos intentos de fundamentación sistemático-absolutos: tanto por una metafísica de la subjetividad, por una fenomenología eidética general, por una dialéctica materialista-histórica, como por una estricta filosofía analítica, con todas sus derivas.

El colapso de todas estas perspectivas univocistas de fundación totalizadoras, en última instancia positivistas, aunado a la consciencia de la "fragmentariedad" (W. Benjamin) y el carácter "perspectivista" (Nietzsche) de cualquier conocimiento y discurso, así como al

evita igualmente la pura especialización, que tiene un no sé qué de incivil y de mentalmente trunco, pues no siente necesidad de una ulterior integración de su ser y su saber. Tal sentido filológico puede adquirirse, y aun alienta por fuerza cualquier entendimiento que se mantenga abierto, vigilante y exigente y no esté deformado;

4) el sentido filológico es condición necesaria e impulso para la precisa evocación y percepción de un hecho, de una idea que eduquen la mente y la habitúen a gustar el placer que produce el ir aumentando nuestro propio patrimonio espiritual" (1969: 44-45).

12 Aquí entendemos por antropología la ciencia o el saber acerca del hombre, de la totalidad compleja del proceso natural/cultural, como el proyecto, siempre inacabado, de una "ciencia del hombre" - que diría Durand, en "El nuevo espíritu antropológico" (1999) - , que su work in progress trascienda la oposición dicotómica entre el hombre tradicional y el hombre moderno. Como sabemos, en nuestro medio académico, por la compleja riqueza de la problemática, opera la división del trabajo de formación e investigación entre la antropología, dedicada principalmente al estudio de las culturas prehispánicas e indígenas, y la sociología, que se ocupa del estudio de las sociedades modernizadas; sin embargo, aquí apelamos a una concepción de la antropología que abarque a ambas y las complemente, en la medida en que ella sería el resultado de la convergencia de los conocimientos del conjunto de las ciencias humanas, de la que tampoco estaría separada la problemática de la que, convencionalmente, se ocupa la llamada "antropología filosófica" como pura materia de la filosofía. 
aparentemente insoluble "conflicto de las interpretaciones" (Ricoeur) en la coordinación de los saberes, no sólo generó - con la quiebra de los metarecit, según Lyotard - el diseminado y equivocista "espíritu de la época" (Zeitgeist) de la posmodernidad, sino la confección, precisamente alternativa a ambas posiciones, del amplio cauce de una hermenéutica filosófica en sentido contemporáneo.

- Es en este último cauce hermenéutico-filosófico, con múltiples afluentes particulares diversificadas, ${ }^{13}$ donde se inscribe la original concepción de la hermenéutica analógica, que viene elaborando ya desde hace veinte años Mauricio Beuchot, y que desde hace más de diez años ha tenido su sede en el Seminario de Hermenéutica, del Instituto de Investigaciones Filológicas. No es lugar aquí para exponer, aunque fuese mínimamente, sus principales lineamientos y perspectivas de aplicación; ${ }^{14}$ bástenos con señalar que la reactivación del pensamiento "analógico" que promueve, y del que ha expuesto su rica genealogía desde la Antigüedad clásica hasta nuestros días, encuentra la phrónesis (o criterio "prudencial") como brújula orientadora de una hermeneusis que busca desarrollar modos diferenciados del uso de la analogía en los diversos campos "textuales" de la investigación humanística. Ciertamente, estableciendo las mediaciones pertinentes, que impidan la unilateralidad o polarización interpretativa: tanto del univocismo, que estrecha los significados del texto hacia una literalidad que coincida exactamente con su "método", concepto o ideología interpretativa, como del equivocismo, que dispersa las específicas significaciones en una arbitrariedad a ultranza y que valida cualquier posible interpretación, es decir, la nihilización de cualquier sentido de verdad del texto.

La conjugación por medio de analogías que establezcan "seme-

13 Por ejemplo: H.-G. Gadamer, P. Ricoeur, G. Bachelard, H. Jonas, H. Zimmer, G. Durand, la constelación de autores del llamado "Círculo de Eranos", H. Blumenberg, M. Foucault, G. Ebeling, G. Steiner, M. Frank, P. Szondi, G. Boehm, H.-R. Jauss, W. Iser, Ch. Jamme, J. Campbell, A. C. Coomaraswamy, A. Ortiz-Osés, E. Trías, L1. Duch, J. Grondin, M. Ferraris, P. Walter, J.-J. Wunenburger, L. Garagalza, P. Lanceros, inclusive dentro de la discusión de la hermenéutica: R. Rorty, K.-O. Apel, G. Vattimo, J. Habermas, J. Derrida, E. Levinas, G. Colli, J.-P. Vernant, G. Deleuze y G. Agamben, entre otros muchos.

14 Véase, por ejemplo, Beuchot 2006; 2007; 2009. 
janzas" entre diferentes significados, textos y órdenes discursivos, pero haciendo resaltar las "diferencias", se encuentra planteada por la hermenéutica analógica como la vía regia para realizar una cuidadosa y matizada transversalidad entre la filosofía y las ciencias humanas; sin descuidar la especificidad de sus particulares campos, atendiendo a ambas problemáticas épocales, y sabiendo, de antemano, que no se avanza en un territorio sin prosperar en el otro.

- Las consideraciones hasta aquí apuntadas, pensamos, pueden servir para enriquecer la conversación sobre el perfil del Seminario de Hermenéutica dentro del Instituto de Investigaciones Filológicas, planteando claramente que el lugar y cometido del Seminario es, en términos generales, el estudio de los problemas y los modelos o "paradigmas" teórico-hermenéuticos y su discusión filosófica, para coadyuvar en el ejercicio interpretativo que las diferentes ramas de la filología cultivadas en el Instituto ${ }^{15}$ llevan a cabo; con el fin de fomentar el diálogo transdisciplinar entre los aportes elaborados desde sus distintos campos de investigación.

Con ello, consideramos que también se contribuye a despejar el equívoco, acaso todavía prevaleciente, acerca de si el lugar adecuado para un seminario de hermenéutica "no estaría mejor en un instituto de filosofía, que en un espacio dedicado a la filología”; pues, como tratamos de aclarar, la hermenéutica no debe ser confundida con una summa filosófica que desde su cumbre teórica externa pretende regir metódicamente las tareas filológicas o tener, desde afuera, la clave de la interpretación correcta. Nada de eso. La hermenéutica, en realidad, nace y se configura en el seno de los problemas filológicos y se enfrenta a los mismos dilemas histórico-culturales; de alguna manera, se constituye como un exacerbamiento y amplificación crítica de la traslación/interpretante de los lenguajes que alcanza a la crisis de la filosofía y las ciencias contemporáneas, las cuales pierden así su

15 El Instituto de Investigaciones Filológicas está conformado por: el Centro de Estudios Clásicos, el Centro de Estudios Literarios, el Centro de Lingüística Hispánica Juan M. Lope Blanch, el Centro de Estudios Mayas, el Centro de Poética, el Seminario de Lenguas Indígenas, el Seminario de Edición Crítica de Textos y el Seminario de Hermenéutica. 
estatuto absoluto de discursos positivos infalibles. La hermenéutica es el elogio de la paciencia, agudeza, erudición y esprit de finesse de la filología, que retroalimenta comprensiva y críticamente su rigurosa disciplina, pero también goce y profundidad humanística; su cometido es complementarlas y ampliar sus horizontes concretos y a la vez universalizables.

Por esta razón, Filológicas aparece como el lugar propicio para la hermenéutica. En su mutuo diálogo fructifica una investigación con vista a ampliar y profundizar la comprensión de los lenguajes, el pensamiento, la creatividad, las pedagogías y las praxis del anthropos.

- Por último, quisiéramos referirnos a las seis líneas de investigación de las particulares problemáticas que, por ahora y en prospectiva, desarrollan y orientan el trabajo de los miembros del Seminario de Hermenéutica, ${ }^{16}$ subrayando que a pesar del rigor exigido por la delimitación de su carácter específico, estas líneas juegan un papel sumamente móvil y flexible, que las hace susceptibles de interrelacionarse entre sí, e inclusive pueden dar lugar, eventualmente, a la emergencia de nuevos campos de exploración:

- Hermenéutica filosófica: en la cual hemos abundado en las notas anteriores, sobre todo se refiere a la génesis y genealogía de los distintos modelos hermenéuticos elaborados a lo largo del transcurrir del discurso filosófico desde la Antigüedad hasta nuestros días, analizados en sus implicaciones epistemológicas y ontológicas. Hace especial hincapié en la comprensión del llamado "giro lingüísticohermenéutico"; en cuanto a su impacto, su novedoso carácter y sus efectos sobre el polémico contexto teórico, ideológico y cultural contemporáneo tanto de la filosofía como del conjunto de las ciencias humanas.

16 Los miembros del Seminario, coordinados por Wendy Phillips (2014-2015) y en la actualidad por Lilian Álvarez, son: Mauricio Beuchot, María Esther Guzmán, Manuel Lavaniegos, Ricardo Martínez Lacy, Shekoufeh Mohammadi, Rafael Mondragón, Juan Nadal, Silvana Rabinovich, Alberto Vital y Verónica Volkow. 
- Hermenéutica cultural: investigación comparativa y transdisciplinar de las manifestaciones de diferentes culturas, situadas histórica y geográficamente; de los códigos o presupuestos ("pre-comprensión”) comunicativos que rigen, consciente o inconscientemente, sus distintas configuraciones discursivas y los ethos en su específica manera de entender y construir el mundo. ${ }^{17}$ Se intenta comprenderlos en su diferencia, conflicto y formas de interrelación, como procesos que dan lugar a nuevas mixturas, mestizajes o modalidades de "hibridación" cultural. Por ello, este enfoque inter-cultural implica también un enfoque intra-cultural, que pretende dar cuenta de los diferentes sustratos y procesos de transformación por los que atraviesa una formación sociocultural en una época históricamente determinada, incluyendo en ello lo que a menudo se denomina como "subculturas". Tal investigación conlleva, asimismo, la reflexión desde una perspectiva trans-cultural, la cual se interroga por las "constantes" antropológicas o "transhistóricas", a lo largo de las más distintas configuraciones históricas, y las diferentes formas específicas en las que los hombres han realizado su metabolismo natural-social. Se trata, entonces, de una triple perspectiva que, precisamente, se pregunta acerca de las condiciones, de estrechamiento y dilatación, de la traductibilidad o interactividad entre las diversas culturas.

- Hermenéutica literaria y del arte: de este vastísimo campo, que prácticamente transversa la investigación de todas las áreas del Instituto, quisiéramos subrayar que justamente por el destacado cúmulo de sus aportes en estos campos, nos permite una visión que, además de ser multicultural, atiende a la enorme complejidad que revisten las dinámicas en el uso y dominio de las lenguas, con sus flujos o bloqueos comunicativo/interpretativos retroalimentados entre sí, dando lugar al surgimiento y desarrollo de nuevos géneros literarios y "paraliterarios" según sus cambiantes necesidades expresivas; desde los textos escritos de las "altas" literaturas hasta el habla cotidiana de los grupos y las personas, con la riqueza de sus pululantes jergas peculiares. El

17 Estos códigos pre-comprensivos entendidos dinámicamente también pueden ser caracterizados a través de la noción acuñada por G. Durand de "cauces del imaginario", o a través de la noción de "vectores de tradición" propuesta por V. Volkow. 
panorama del cultivo del idioma, su relación con la lectura/escritura efectiva y las diferentes estrategias discursivas en su sintaxis, poética, difusión y recepción, atañen directamente al proceso de la vida literaria y conforman la "argamasa" o, mejor aún, la sangre en el sistema circulatorio, del "mundo de la vida" cotidiana de las sociedades; pues sus flujos son de carácter inminentemente pedagógico — tanto en la educación "formal" como en la "informal" diseminada por todos los ámbitos-, y de su consistencia e intensidad depende la calidad de su empalabramiento del mundo. Todo ello, por lo demás, quedaría trunco en esta visión si no se investigan los diferentes efectos que las nuevas tecnologías mediáticas han introducido en nuestra época, de hecho, inervando bajo su "red" a todas las esferas socioculturales. ${ }^{18}$

Respecto del señalamiento relevante hacia el camino del arte o de las manifestaciones de las diversas artes, no sólo se encuentra presente en la impronta de poiesis creativa en el seno de las artes del signo o de la poesía y la narrativa, sino también en la hermeneusis de todos los lenguajes artísticos - plástico/visuales, musicales, arquitectónicos, dancísticos, teatrales, fotográficos, cinematográficos, etc.- , que con sus configuraciones imaginales en el espacio/tiempo, tanto afectivo/sensibles como reflexivas, producen, tal vez, los mensajes más complejos y a la vez más personales y singulares de una cultura, inundando la apertura de sus cauces imaginarios. Abarcan, pues, todos los ámbitos de intensificación de las "representaciones simbólicas", de la "iconicidad" y de la "fōné-tiempo" de la música. De tal forma que la "artisticidad" y la polémica estético/artística no puede quedar al margen de la investigación filológica y hermenéutica. A su vez, en estas temáticas se buscará el diálogo con el Instituto de Investigaciones Estéticas, la Facultad de Artes y Diseño, la Facultad de Música, el Centro Universitario de Teatro y el Centro Universitario de Estudios Cinematográficos, todos ellos de la UNAM.

- Hermenéutica del símbolo, el mito y la religión: una de las problemáticas fundamentales, sin duda, re-abiertas por el "giro hermenéutico" que, con base en una revalorización de las configuraciones

18 Véase Vital 2012. 
simbólicas - cuyo "excedente de sentido" apunta a evocar las dimensiones trascendentes - de los textos, las imágenes y las prácticas religiosas (tanto en sus formaciones "populares" más espontáneas, en las instituidas eclesiales, como en sus más sofisticadas formas de especulación teológica), viene a plantear de nuevo la necesidad de la comprensión de los fenómenos religiosos. Investigación hermenéutica de las específicas mediaciones religiosas que intenta ir más allá de la interpretación "reduccionista" propia de la crítica ilustrada, filosófico-científica, de la religión, así como de las interpretaciones teológicas "confesionales" o canónicas. La hermenéutica del símbolo, el mito y la religión ante el fracaso de la noción - a menudo entendida absoluta y equívocamente - de secularización radical o total "desencantamiento del mundo" (Max Weber), que pretende abarcar y dar razón tanto del devenir histórico de las tradiciones religiosas y sus inseparables vertientes exegéticas, como de la emergente proliferación de modalidades de religiosidad de nuevo tipo. Este campo presenta una virulencia enigmática insoslayable en el horizonte tardomoderno, agudamente marcado por el llamado "retorno de lo religioso" y la violenta incidencia de teologías-políticas en los conflictos localglobales. ${ }^{19}$

- Hermenéutica jurídica: con el antecedente de aplicaciones de la hermenéutica analógica al campo del derecho, ${ }^{20}$ se busca propiciar enlaces con el Instituto de Investigaciones Jurídicas de la UNAM, así como con los investigadores de derecho romano del Centro de Es-

19 No sólo para esta línea de investigación sino para el conjunto de las seis mencionadas, se hace hincapié en dirigirlas, con urgencia, hacia la abierta captación, con toda su virulencia, de las fluidas redes comunicativas y diseminaciones que conforman las dinámicas socioculturales de la actualidad, y afectan la cotidianidad individual y colectiva. Por consiguiente, presentan afinidades tanto con el doble enfoque de "glocalilización" (global-local), pregonado por Zygmunt Bauman para la comprensión de la modernidad líquida propia del extremo contemporáneo, como con la perspectiva "rizomática" de las alternativas (Deleuze/Guattari) y la exploración crítica de los "micropoderes" (Foucault), que operan efectivamente en los horizontes (inteligibilidades-visibilidades) de los textos y las acciones. En la secuencia de estos énfasis heurísticos, también se inscribe la sostenida investigación de S. Rabinovich sobre la diseminación de "heteronomías y utopías" éticas, políticas y religiosas.

20 Por ejemplo, los trabajos de Napoleón Conde. 
tudios Clásicos, a fin de reanimar uno de los campos más antiguos y necesitados de continua interpretación prudencial, como es el de la legalidad que rige los derechos y obligaciones que norman la conducta ciudadana, en relación con los conflictos y deliberaciones de la gestión civil y política, incluida la compleja gama de escenarios y discursos de legitimación así como el uso de la violencia; inquiriendo en tanto acerca de las posibilidades efectivas de justicia. Y sin dejar de observar la alarmante situación actual por la que atraviesa el país, donde la "impunidad" criminal coaligada con la político-estatal parece haber colapsado por completo el sistema legal de impartición de justicia y de protección de los elementales derechos humanos de las personas.

- Hermenéutica de la historia y del discurso periodístico: es también un inmenso y complejo campo de investigación, el cual, por supuesto, transversa complementando a las otras líneas expuestas, pues pone el acento en el carácter plenamente historizado de todas las discursividades socioculturales, de sus perspectivas interpretativas y del fluídico tejido de sus transmisiones, incidiendo en la efectualidad de las praxis, explorándolas, así, en su insoslayable carga "política". Es decir, enfocando, a la vez, la reconstrucción de la memoria ("presente del pasado") y la prefiguración proyectiva ("presente del futuro") en su convergencia constructiva de la actualidad ("presente del presente"), interpretada ésta por los discursos, siempre "interesados", en sus posibilidades o coyunturas de transformación, en una u otra dirección; y esto explorado no sólo respecto de la exclusiva esfera político-estatal, sino de cualquier ámbito de actividad humana.

Si los discursos propiamente dichos de la historia se ocupan de la investigación y evaluación de la correspondencia entre los procesos históricos de "tiempo largo" y "tiempo corto", ampliando y nutriendo la consciencia histórica como factor decisivo para su transformación, la dimensión específica del periodismo abarca la multitud de textualidades polémicas que proyectan y fabrican, formatean, el "tiempo real" - con inmediatez cuasi-instantánea - de la opinión pública, incidiendo de manera directa en la toma de decisiones y 
su legitimización de cara a los eventos coyunturales concretos que afectan la vida social.

La corporeidad psicosocial atravesada por intensas conminaciones de multitud de "textualidades" (palabras-conceptos-textos-imágenes) o discursividades, cifradas en estereotipados usos lingüísticos, constituye el sismógrafo de esta dimensión; que en el extremo contemporáneo se encuentra determinada, de manera radical, por la expansión de las nuevas tecnologías de la comunicación y la información, las cuales han venido a transmutar las tradicionales formas de elaboración y transmisión culturales y, con ello, los sistemas de necesidades, los valores "pre-comprensivos", que daban criterios de orientación, e iluminaban con su sentido la cotidianidad y los proyectos de vida de las personas. La investigación de esta intrincada gama de hibridaciones textuales y desplazamientos funcionales de la comunicación y sus interpretaciones, con sus poderosos efectos sobre el entendimiento de la realidad y del mundo, adquieren así un relieve de extrema urgencia para el horizonte de nuestros días.

\section{Bibliografía}

Bataille, Georges (1989). La experiencia interior. Madrid, Taurus.

Beuchot, Mauricio (2006). Lineamientos de hermenéutica analógica. México, Conarte.

- (2007). Hermenéutica analógica, símbolo, mito y filosofía. México, Universidad Nacional Autónoma de México, IIFL.

- (2009). Tratado de hermenéutica analógica. Hacia un nuevo modelo de interpretación. México, Universidad Nacional Autónoma de México, FFYL/Ítaca.

Duch, Lluís (1998). Mito, interpretación y cultura. Aproximación a la logomítica. Barcelona, Herder.

- y A. Chillón, (2012). Un ser de mediaciones. Antropología de la comunicación. Vol. 1. Barcelona, Herder.

DuRAND, Gilbert (1999). "El nuevo espíritu antropológico”, en Ciencia del hombre y tradición, Agustín López y María Tabuyo (trads.). Barcelona, Paidós: 259-282.

FABRIS, Adriano (2001). El giro lingüístico y análisis del lenguaje. Madrid, Akal.

FERraris, Maurizio (2002). Historia de la hermenéutica. México, Siglo XXI. 
GADAMER, Hans-Georg (1977). Verdad y método. Salamanca, Sígueme.

- (1997) "La diversidad de las lenguas y la comprensión del mundo", en Hans-Georg Gadamer y Reinhart Koselleck (comps.), Historia y hermenéutica. Barcelona, Paidós: 107-125.

Grondin, Jean (1999). Introducción a la hermenéutica filosófica. Barcelona, Herder.

HADOt, Pierre (2009). La filosofía como forma de vida. Conversaciones con Jannie Carlier y Arnold I. Davison. Barcelona, Alpha Decay.

HeIDEGger, Martin (1987). Del camino al habla. Barcelona, Serbal.

- (2005). Desde la experiencia del pensar. Madrid, Abada.

- (2008). Ontología de la facticidad. Madrid, Alianza.

JAKOBSON, Roman (1975). Ensayos de lingüística general. Barcelona, Seix Barral.

JUNG, C. y K. KERÉNYI (2003). Introducción a la esencia de la mitología. Madrid, Siruela.

NiETZSCHE, Friedrich (1963). "Consideraciones intempestivas: De las ventajas y desventajas de los estudios históricos para la vida", en Friedrich Nietzsche. Obras completas. Vol. I. Buenos Aires, Aguilar.

Pizarnik, Alejandra (1992). Semblanzas. México, Fondo de Cultura Económica.

Righi, Gaetano (1969). Historia de la filología clásica. Barcelona, Labor.

Steiner, George (2001). Después de Babel. Aspectos del lenguaje y la traducción. México, Fondo de Cultura Económica.

Vital, Alberto (2012). Quince hipótesis sobre géneros. México, Universidad Nacional Autónoma de México, IIFL/Universidad de Colombia.

Wittgenstein, Ludwig (1973). Tractatus lógico-philosophicus. Madrid, Alianza. 